A systematic review of social support in youth sport

Daragh Sheridan, Pete Coffee and David Lavallee

School of Sport

University of Stirling 


\begin{abstract}
The purpose of this study was to provide a systematic review of studies concerning social support in youth sport from 1990 until 2013. A total of 73 studies were evaluated and are reported in four sections: sample characteristics; research designs; social support provider type; and key correlates relating to social support. Samples ranged from one to564. Studies examined a wide range of sports, ages (10 - 22 years) and competition levels. Studies used qualitative (23\%), quantitative (75\%), and mixed-model (2\%) designs. The main conclusion is that recent advances in the conceptualization of social support have generated a more diverse set of methods to examine the quantity and satisfaction of social support in a sports context. Coaches were identified as the most prevalent provider of social support through offering participants unique forms of tangible, informational, emotional and esteem support. Furthermore, coach, parent and peer support plays a significant role in shaping youth sport experiences both from a positive (athlete motivation levels, elite sport participation) and negative perspective (drop out). The discussion focuses on the current status of the research area, limitations, suggested practical implications (e.g., providing proactive support) and future research directions (e.g., examining optimal support matching).
\end{abstract}

Keywords: parents, coaches, peers, networks, interpersonal support 


\section{A systematic review of social support in youth sport}

Research suggests social support involves "an exchange of resources between at least two individuals perceived by the provider or recipient to be intended to enhance the well being of the recipient" (Shumaker \& Brownell, 1984, p.13). Support derived from key interpersonal relationships (e.g., coaches, parents, peers) in a sporting context has been identified as an important resource for athletes. The quality and type of social support an athlete perceives and receives is linked with recovery from injury, youth sport participation, burnout, self-confidence, and performance (Bianco \& Eklund, 2001; Holt \& Hoar, 2006; Rees, 2007).

Although there is an increased awareness and promotion of social support in sport (Jowett \& Lavallee, 2007), research to date has not completed a systematic review of social support in a youth sport context. The case for conducting such a review of the evidence-base is strengthened due recent developments in the research field. The construct of social support has been diversified in order to consider the structural (number and type of relationships) and functional (perceived and received support) aspects of interpersonal relationships (Lakey, 2010). This multi-dimensional conceptualization of social support has recently generated a more diverse set of methods to examine the quantity and satisfaction of social support in a sports context (Freeman, Coffee \& Rees, 2011).

A review of the extant literature points to a rapidly evolving research area. In the 1990s, research into the theme of interpersonal relationships in sport was largely under developed (Iso - Ahola, 1995). Over a decade ago, Wylleman (2000) responded to this gap and reviewed the research area concerning interpersonal relationships in sport and exercise. The author found a lack of empirical evidence published in sport psychological journals and small number of psychometric instruments on relationships available to sports psychologists. Following this the research area has continued to expand, especially over the past 10 years. Jowett and Wylleman (2006) reported significant progress in the quality and quantity of studies in the research area. The authors also identified a number of key challenges in studying the theme of interpersonal relationships in sport and exercise. Such challenges include expanding the theoretical approaches used to study 
relationships given the lack of theoretical diversity in the literature. Moreover, the authors called for the use of a lifespan approach to study how athletes' interpersonal relationships with coaches, peers, parents, siblings and significant others evolve before, during and after their sport career. Finally, the authors called for the development of more sophisticated statistical tools to measure the relationship data at different levels (individual, dyadic and group).

In more recent years, the literature has included several publications on social support and interpersonal relationships in sport (Jowett \& Lavallee, 2007; Lavallee \& Wylleman, 2007; Smith \& Bar-Eli, 2007). During this period, several book chapters have been dedicated to the theme of youth sport and how key interpersonal relationships impact the development of youth participants (Ntoumanis, Vazou \& Duda, 2007; Salmela, Young \& Kallio, 2000; 2007; Smith, 2007; Smith, Smoll \& Curtis, 2007; Weiss, Smith \& Theeboom, 1996; White 2007; Wylleman, De Knop, Ewing \& Cumming, 2000, 2007; Wylleman, De Knop, Verdet \& Cecic-Epic, 2007). Research has highlighted that youth sport participants are most likely to experience positive developmental outcomes when interactions with coaches and parents are characterized by positive and informational feedback, appropriate role modelling and autonomy-supportive engagement styles (Weiss \& Wiese-Bjornstal, 2009). Furthermore, positive relationships with teammates and friends are associated with favourable self-perceptions, emotions, self-determined motivation, and moral development (Smith \& McDonough, 2008). These recent findings concerning the positive influence of social support in a youth sport context point to a strong basis for the completion of a systematic review in order to effectively share the best available evidence in the research area.

The purpose of the current study therefore was to conduct a systematic review of social support in youth sport focusing on examining the populations in which social support has been explored, the key questions that have been posed, and the research strategies that have been deployed. As highlighted by similar systematic reviews (Goodger, Gorely, Lavallee \& Harwood, 2007; Park, Lavallee \& Tod, 2012), this study offers an opportunity for researchers to share the available evidence by identifying appropriate theories to develop future research directions and intervention strategies, as well as raise awareness of the range of research methods 
employed in the study area. Specifically, the review aims to provide a summary of sample characteristics, the key relationships of social support, and research designs employed up to March 2013.

\section{Method}

\section{Sources}

The search strategy was initiated in March 2013 and initially included the use of the following electronic databases: Google Scholar; Science Direct; Scopus; PsycInfo; Proquest; and Pubmed. The rationale for using these databases relates to their prominent usage in other systematic reviews (Goodger et al., 2007; Park et al., 2012; Sallis, Prochaska, \& Taylor, 2000) using a similar review protocol. Additional citations were subsequently gathered through reading the reference lists of articles already obtained. Keyword combinations employed in the search strategy included the following 'Youth Sport', 'Social Support', 'Interpersonal Relationship (s)' 'Transition', 'Systems', 'Networks', 'Athlete', 'Coach', 'Parents' 'Peers' 'Teammate'.

Studies needed to: (a) contain empirical data concerning youth sport samples mean age $10-22$ years as there is a broad consensus within the research that the youth age category is from $10-22$ years (Santrock, 2010); (b) be related to social support in youth sport; and (c) be peer reviewed and published in English. These inclusion criteria were applied to journal articles and published conference proceedings and imposed no limits on characteristics of samples and research designs.

\section{Procedure}

Hard copies of the studies were gathered initially and assessed against the inclusion criteria. After sourcing the studies, the same systematic review protocol as used by Sallis et al., (2000), Goodger et al.,(2007) and Park et al., (2012) was applied to this analysis. The rationale for applying this review protocol is reflected in the original review completed by Sallis et al. The authors completed a systematic review of correlates of physical activity in a similar aged adolescent population, which enabled a full range of potential correlates to emerge during the review. Furthermore the review method enabled a range youth social support correlates involving siblings, teachers, parents, peers and coaches to emerge across a diverse range of studies. 
The protocol for this review method included the creation of Table 1 and Table 2 in order to classify the: (a) research design; (b) sample characteristics; and (c) key correlates relating to social support in a youth sport context. As highlighted by Sallis et al. (2000), the rationale for this review method were to: (a) identify detailed methodological features of the studies in order to help researchers develop better methods in the future; (b) examine the characteristics of the sample populations in order to help identify sampling gaps; and (c) analyze the key factors related to social support in a youth sport context and identify the evidence base for theories and models to provide practical implications for both future research directions and interventions strategies.

\section{Assignment of Bibliography Numbers}

As part of the analysis process, each study was assigned a bibliography number. These numbers were based on the number of independent samples as contained in the article. If an article contained more than one independent sample then each independent sample contained in the article was given a separate bibliography number. For instance, when the same data was published more than once, each independent sample was assigned the same bibliography number.

\section{Research Designs, Sample Characteristics, Theoretical Approaches}

Samples were analyzed by size, gender, competitive level, type of sport, age, type of support provider and location. Studies were also classified by data collection method, research design and theoretical approach. The data collection method category enabled the review process to take into account the reliability/validity of the social support measures used. Moreover the theoretical approach category enabled a review of the guiding theoretical framework underpinning the research design. Additionally if a sample was published more than once but assessed a different correlates on each occasion, we assigned the same bibliography number with an attached sub number.

\section{Correlates of Social Support in a Youth Sport Context}

The selection and analysis of the studies was monitored throughout the review process. The authors met on three occasions in March 2013 to review an initial search long list containing 104 articles. Each article was 
examined for key variables and their association with social support (cf. Sallis et al., 2000). This review process involved an individual study analysis whereby each author assessed each study against the agreed inclusion criteria. Key references to social support in both the study abstract and methodology were discussed and agreed. As a result 39 articles (38\% of the initial studies) were excluded during this process.

Table 2 provides a summary of the key correlates relating to social support in a youth sports context. Only correlates containing more than three independent samples are included in Table 2. Some correlates that were conceptually similar were combined if there were not enough studies to examine the variables individually. Finally, the dyadic aspect of the social support determinants were reflected in the creation of key social support provider categories. The following three social support provider categories were included: coaches; parents; and peers. Once the correlates were categorized appropriately, we examined the direction of association of the variables based on study findings. In order to gauge the direction of the correlate, the following coding rules were applied if the correlate was positive (+), negative (-), no association (0), or indeterminate (?). The last stage of the analysis was to determine the strength of the association for each correlate by calculating the percentage of samples supporting the direction of the association. The guidelines for weighting the strength of these associations were provided by Sallis et al. (2000). Correlates with a strength weighting between the following percentage bands were labeled as follows: $0-33 \%=$ no association, $34-59 \%=$ indeterminate or inconsistent and 60-100\% = positive or negative association.

\section{Results}

\section{General Findings}

A total of 104 articles were identified from the initial research process. This was reduced to a final list of 65 articles, which met the inclusion criteria. These articles were published in peer-reviewed publications. Among the 65 papers, four articles contained two independent samples (Freeman, Coffee, \& Rees, 2011, Jowett, 2009, Le Bars, Gernigon, \& Ninot 2009; Rhind, \& Jowett 2012) whilst two articles contained three independent samples (Rees, Freeman, Bell \& Bunney 2012; Weiss \& Smith, 1999). As a result, a total of 73 
studies were reviewed and reflected in a final bibliography table as contained in Table 1 and Table 2. Among 65 articles, 6 were published in the 1990s, with the remaining 59 articles published between 2000 and 2013.

\section{Research Designs}

Table 1 represents the study design and sample characteristics across the 73 studies. Researchers have used quantitative (55), qualitative (17) or a combination of both (1) to examine the social influences across a series of key youth sport relationships. Sagar, Busch, and Jowett (2010) was the only study to use a mixed approach using both qualitative and quantitative methods. Two studies employed a longitudinal approach while cross sectional methods were employed in the remaining 63 studies. Well over two thirds of the studies (47) collected data via questionnaires and the rest (18) via interviews. The questionnaires used can be divided into three categories: (a) questionnaires relating to social support (23), (b) instruments which examine general psychological variables (21); and (c) surveys which were considered non related to social support or general psychology (4). The most frequently used questionnaire was the Coach Athlete Relationship Questionnaire (CART-Q; Jowett \& Ntoumanis, 2004). This questionnaire was used in six studies (Adie \& Jowett, S. 2010; Felton \& Jowett, 2012; Jowett, 2006, 2009; Lafrenière, Jowett, Vallerand, \& Carbonneau, 2011; Riley, \& Smith 2011). Across all the studies, 29 employed a social theoretical approach followed by a motivational approach (19), developmental approach (10), cognitive approach (4), and behavioral approach (2). One study did not indicate a theoretical approach.

\section{Sample Characteristics}

The total number of participants was 11,847 . This participant profile was broken down into 3 main relationship consistencies; athletes (10,975), coaches (467) and parents (405). The range of sample sizes was between 1 and 564. The number of studies with fewer than 50 participants was 15, and 44 studies were conducted with samples between 51 and 300. Five studies had samples between 301 and 500 and two studies examined population sizes greater than 500 participants.

Across the studies, 59 included both genders, 8 included male participants only, 4 included female participants and gender was not specified in 2 studies. Studies contained in the review reflected a wide range of 
competition levels, including recreational (5), high school/college (1), club (15), elite (17), professional (2), amateur (1). Mixed level competition was examined in 25 studies while in seven studies the competition level was not identified.

Researchers have investigated individual sports (21), team sports (16), or a combination of both (29) and seven did not report any type of sport. In 36 studies the athletes were aged between 10 and 17, in 29 studies athletes were aged between 18 and 22 while 8 studies did not report the age of participants. The majority of studies were completed were conducted in Western countries (41 in Europe, 29 in North America and 1 in both Australia and Japan). Two studies did not identify the origin of the sample population.

\section{Correlates of Social Support in Youth Sport}

Across the studies we identified 23 correlates related to social support in a youth sport context. These variables were reduced to 16 during the analysis. The majority of studies (59) examined positive aspects concerning social support while 12 studies examined negative social support dimensions concerning burnout (5), drop out (3), interpersonal conflict (3) and fear of failure (1). One quarter (16) of the studies investigated the link between social support and athlete motivation. The other remaining studies examined a range of intrapersonal constructs (self esteem, self confidence, and self concept) and key developmental outcomes (sports participation, physical activity, talent development and friendship) concerning social support in youth sport. The athlete coach relationship was the most examined single dyadic support relationship with 18 studies examining the determinants of this key support relationship. The parent support relationship was exclusively examined in 13 studies while peer/team mate support was examined in 10 studies. Coach and parent support was the most examined multi relational support influence with eight studies examining this social support context. Only one study (Jowett \& Timson-Katchis, 2005) examined the direct effect that a dyadic support relationship had on another dyadic support relationship. Moreover, five studies examined an athlete's perception of a key triadic support network including parents, coaches and peers (Keegan, Spray, Harwood, \& Lavallee 2010; Le Bars, Gernigon \& Ninot, 2009; Pummell, Harwood \& Lavallee, 2008; Wylleman, De Knop, Sloore, Vanden Auweele, \& Ewing, 2003) 


\section{Factors Relating to the Type and Quality of Social Support in Youth Sport}

We identified three main social support provider categories relating to the exchange of support resources across three key support constituents namely coaches, parents, and peers. The basis for this categorization is reflected in the athlete lifespan model, which identifies parents, peers and coaches as significant support relationship at the psychosocial development level during adolescent development (Wylleman \& Lavallee, 2004).

\section{Coach support.}

Coaches play a critical role in influencing the experiences of young people with whom they interact (Greendorfer, 2002). Coaches can offer support and guidance to athletes that ultimately facilitate the formation of strong bonds (Jowett \& Poczwardowski, 2007). This support has been shown to impact enjoyment, motivation and the development of key competences (Côté \& Fraser-Thomas, 2007).

Social support provided by coaches accounted for the highest number of correlates (7) across the review. Table 2 shows that the social support correlates and their directions relative to coach support. We identified 7 variables associated with the athlete coach relationship, including quality of the athlete relationship, athlete motivation, elite sport participation, burnout, athlete satisfaction, drop out and athlete development. These variables are presented below in the order of the number of studies, which examined each correlate.

Furthermore the findings from this review show that coaches interacted with parents and peers in both similar and unique ways. For example Keegan et al. (2010) identified that parents and coaches influencing player motivation displayed similarities across a series of key support behaviors including leadership style, evaluative feedback, emotional and affective responses and pre performance motivating behaviors. Findings from Taylor and Bruner (2012) showed that a coach's ability to establish rapport with a group of players reduced social exclusion amongst a group of youth participants.

\section{Quality of athlete relationship.}

A total of 12 independent studies demonstrated links between coach support and the quality of the athlete coach relationship. Eleven studies indicated that the overall association between coach support and the 
quality of the athlete relationship was positive. Five studies examined the athlete coach relationship as conceptualized through the 3Cs Athlete Coach Relationship Model (Jowett, 2007) highlighting closeness, commitment and complementarity as three key constructs reflecting the quality of the athlete coach relationship. The Quality of Relationship Inventory (QRI) (Pierce, Sarason, Sarason, Solky-Butzel \& Nagle, 1997) was used by two studies (Jowett, 2009) to validate the 3Cs model in a sample of student athletes.

The athlete perception of the quality of coaching support was examined by three studies (Rees et al. 2012). A self reported questionnaire (Freeman \& Rees, 2009) was used to assess emotional, esteem and informational forms of coaching support designed to reflect the supportiveness of coaches. Results show that support perceptions were reflected in all three components however the largest contributor to the perception of the quality of the relationship was in the relational component between the athlete and coach. This article helped to inform our understanding of perceived coach support by demonstrating the relative contributions of perceiver, target, and relational components towards the quality of the athlete relationship.

Two studies examined the key strategies for maintaining the quality of the coach athlete relationship (Rhind \& Jowett, 2012). This article developed initial evidence for the reliability and validity of a measure for the use of strategies designed to maintain the athlete coach relationship. The Coach Athlete Relationship Maintenance Questionnaire (CARM - Q) was developed in order to examine the use of maintenance strategies for maintaining the quality of the athlete coach relationship. This article found that conflict management, openness, motivation, positivity, advice, support, and social networks are key strategies for maintaining the quality of coach-athlete relationships.

\section{Athlete motivation.}

Motivation concerns why people think and behave as they do (Weiner, 1992). Eleven studies examined the influence that coaching support had on athlete motivation. The overall association was positive with four studies reporting inconsistent associations. Self-determination theory (Deci \& Ryan, 1985; Ryan \& Deci, 2000) was adopted by six studies to investigate the link between the perception of the coach athlete relationship and an athletes' motivation. Five studies highlighted a positive association between coaching support and an 
athlete's ability to feel autonomous and competent (Adie \& Jowett, 2010; Gould, Flett \& Lauer, 2012; Riley \& Smith, 2011; Smith, Balaguer \& Duda, 2006; Taylor \& Bruner, 2012). Specifically, these studies highlighted a coaching approach that focused on a task or mastery approach that enabled athletes to view their coaches as more cooperative, committed and close in their relationships. Conversely, Isoard - Gautheur et al. (2013) contended that young talented athletes perceiving an ego-involving coaching climate that emphasized mastery avoidance goals at the beginning of the season had a higher risk of experiencing burnout symptoms at the season's end.

Felton and Jowett $(2012,2013)$ examined the mediating role of social factors on the associations between attachment styles and basic psychological needs satisfaction within both the coach and parent relational contexts. Results showed an inconsistent association across both relational contexts. However, it appears that positive and supportive behaviors from both the coach (social and autonomy support) and parent (non conflict and non controlling support) are associated with a mechanism that helps 'avoidantly attached' athletes engage in a supportive interpersonal environment.

The cultural difference between athletes from western countries and eastern countries was examined by Alfermann, Geisler, and Okade, (2013). The authors examined key aspects of both athlete communities concerning their goal orientation and perception of coaching support. Results showed an inconsistent association in that German athletes reported more instruction, positive feedback and social support in comparison to their Japanese counterparts. However, Japanese athletes perceived their training environment to be more performance oriented in comparison to the German athletes. The authors contented that this difference was due to the socialization of young Japanese athletes into sport whereby a winning mindset is developed.

Keegan et al. (2010) completed the only qualitative study examining the motivational atmosphere in youth sport across the coach, parent and peer triad support system. The focus group approach offered detailed and important insights into the specific support behaviors influencing the motivation of athletes. For example the findings showed the motivational influence arising from coaches' and parents' were related to their specific support role. Coaches motivated athletes by instruction/assessment, whilst parents motivated athletes through 
their support and facilitation actions. The study also showed peers influenced athlete motivation through competitive behaviors, collaborative behaviors, evaluative communications, and through their social relationships. However the authors noted that it was impossible to establish any direct or corresponding link between the 3 relationship sources and an effect on athlete motivation.

\section{Elite sports participation.}

Participation in elite sport can offer a substantial challenge to young athletes both from a physical and psychological perspective (Hollander, Myers, \& LeUnes, 1995). Five studies examined the association between coaching support and elite sport participation. Four studies identified a positive association while the remaining study was deemed inconsistent (Bruner, Munroe-Chandler \& Spink, 2008). Coaches were deemed to play a positive role in facilitating an athlete's transition from recreational sport into elite sport (Baxter-Jones \& Maffulli, 2003; Pummell et al., 2008). Le Bars et al. (2009) identified that the motivational climate created by a coach was a predictor of elite sport continuation. This longitudinal study suggested that coaches who created a task-involving climate had a positive effect on an athlete's persistence in elite sport.

In contrast, Bruner et al. (2008) identified an inconsistent associated between coaching support and elite sport participation. This qualitative study completed a preliminary examination of the transition experience of young athletes starting a career in elite sport. Athletes identified coaches as an important support during the transition into elite sport. However, several athletes perceived coaching feedback as over critical and as a result a negative influence on the athlete confidence was identified.

\section{Athlete burnout.}

Athlete burnout is a multi dimensional psychological syndrome characterized by dimensions of emotional and physical exhaustion, reduced sense of accomplishment and a devaluation of the sporting context (Raedeke, 1997; Raedeke \& Smith, 2001, 2009). Three studies examined the link between coaching support and athlete burnout (Gould, Tuffey, Udry \& Loehr, J. 1996; Isoard-Gautheur, Guillet-Descas \& Duda, 2013; Strachan, Côté \& Deakin, 2009). Two studies indicated a positive correlation between coaching support and athlete burnout. Coaches who lessened athlete input into training were deemed to have a negative influence on 
athlete motivation (Gould et al., 1996). While Isoard-Gautheur et al. (2013) extended the link between athlete motivation and burnout and examined the influence of the coaching climate on athlete burnout. Findings indicated that young athletes perceiving an ego-involving climate emphasizing mastery avoidance goals at the beginning of a season had a higher risk of burnout by the end of the season. Such a coach support climate corresponds to a focus on not doing worse than previous performance or not making mistakes (Elliot \& McGregor, 2001).

In contrast to the psychological dimensions of burnout, Strachan et al. (2009) identified that physical exhaustion was a key differentiator in influencing burnout for those athletes specializing in sport. Although coaching support was not identified as a key association with both physical exhaustion and burnout, the study authors did highlight a coach's responsibility to consider the psychological and social outcomes of an athlete's involvement in elite sport.

\section{Athlete satisfaction.}

Three articles examined the relationship between perceived athlete satisfaction and coaching support. The association was largely positive with one study reporting an inconsistent relationship between coaching support and athlete satisfaction. Lorimer and Jowett, (2009) investigated the empathic accuracy of 60 coachathlete dyads, its antecedents (meta-perceptions of relationship) and consequences (perceptions of satisfaction). The results indicated an association between meta-perceptions of the athlete coach relationship and increased empathic accuracy. Increased empathic accuracy was in turn associated with higher levels of relationship satisfaction. Moreover, Lafrenière et al. (2011) reported a positive association between the athlete coach relationship and general athlete happiness. Through assessing a coach's passion for coaching, results showed that harmonious passion for coaching positively predicted autonomy-supportive behaviors toward their athletes, while obsessive passion for coaching positively predicted controlling behaviors. Moreover, autonomysupportive behaviors predicted high quality coach athlete relationships as perceived by athletes that, in turn, positively predicted athletes' general happiness. In contrast Weiss and Fretwell, (2005) explored the contentious nature of a parent coach/child athlete relationship. Results showed an inconsistent association 
between the athlete coach relationship and athlete satisfaction. Multiple costs and benefits of being coached by one's father were identified.

\section{Athlete drop out.}

Drop-out refers to the premature sport career termination among young athletes before they reach their full potential (Alfermann, 1995). All three studies that examined the relationship between athlete drop out from sport indicated a positive association with coaching support. Le Bars et al. (2009) completed two studies stressing the importance of coaches, peers and parents in creating a motivational climate that safeguards athlete persistence in sport. Findings indicate that a task-involving climate involving all social support agents predicted athlete persistence in sport. Such a support climate corresponds with key support behaviors including challenging task choice and the promotion of greater effort and persistence regardless of perceived ability. Salguero, Gonzalez-Boto, Tuero and Marquez (2003) examined the reasons for drop out among 62 swimming drop outs. Athletes reported a main reason for dropping out concerned the fact that they 'did not like the pressure' and 'did not like their coach'. The study supports the previous association between coaching support and athlete drop out. The study determined that a disliking for the coach was ranked seventh amongst a list of 29 reasons for dropping out.

\section{Athlete development.}

Previous coaching motivational (Smith, Smoll, Cumming, 2007) and caring climate research (Fry \& Gano-Overway, 2010) suggests that coaching support has an important impact on the personal and social development of young people. Three studies indicated a positive relationship between athlete development and coaching support. Gould et al. (2012) assessed the relationship between psychosocial development and the sports climate and found that the more coaches create a caring, mastery oriented environment the more likely positive youth developmental gains emerge. Philippe et al. (2011) took a qualitative approach and explored the evolving nature of the athlete coach relationship. The authors concluded that the development of the athlete coach relationship was beneficial to an athletes' personal growth, mental strength and athletic development. Wylleman et al (2003) examined the athlete perception of athlete coach parent relationships in their 
psychological network. The study deemed that both coach and parent relationships to be positive and constructive from an athlete development perspective.

\section{Parent support.}

Parents play a role in the development of youth participants in sport. Research to date has examined multiple ways in which parents can support the development of talent (Bloom, 1985, Côté, 1999; Csikszentmihalyi, Rathunde, Whalen, \& Wong, 1993; Durand- Bush, Salmela, \& Thompson, 2004; Gould, Dieffenbach, \& Moffet, 2002). However their involvement often has negative outcomes including stress for youth-sport participants (Gould, Eklund, Petlichkoff, Peterson, \& Bump, 1991; Gould, Wilson, Tuffey, \& Lochbaum, 1993; Scanlan \& Lewthwaite, 1984). Table 2 shows that the social support correlates and their directions relative to parent support. We identified 5 variables associated with the athlete parent relationship, including, athlete motivation, elite sport participation, athlete development, physical activity and drop out. These variables are presented overleaf in the order of the number of studies, which examined each correlate.

Furthermore, the findings also indicated that parents interrelate with coaches and peers in shaping the environment experienced by youth participants. For example Jowett and Timson-Katchis (2005) explored the influence that parents have on athlete coach relationship. The study concluded that parents provided a range of information, opportunities and emotional support, which positively impacted the athlete coach relationship. Carr (2009) investigated the link between the parent athlete relationship and peer friendship. Athlete parent relationships that displayed secure and attached characteristics had a positive effect on sporting friendships amongst youth peers.

\section{Athlete motivation.}

In the studies examined in this review, parent support was positively associated with athlete motivation. Four studies indicated a positive relationship between parent support and athlete motivation (Kavussanu et al., 2011; Keegan et al., 2010; Ullrich-French \& Smith, 2006, 2009). In a qualitative study, Keegan et al. (2010) highlighted parent spectating as motivationally relevant factor for young athletes. Moreover, the motivational climate that parents created was identified as another key factor in influencing athlete motivation. Findings 
suggest that a parent initiated motivational climate focused on a task orientation approach has a positive influence on athlete motivation and resultant sport achievement (Kavussanu et al., 2011). This finding was further backed by Ullrich-French and Smith (2006) when findings showed that a positive perception of parent support was associated with positive motivational outcomes. A subsequent study completed by the same authors in 2009 examining the social and motivational predictors of continued youth sport participation found that the combination of mother relationship quality and peer relationships successfully predicted sports continuation on the same team.

In contrast, research assessing the attachment characteristics between parents and athletes identified a negative association between an insecure attachment style and athlete motivation (Felton \& Jowett 2012, 2013). Such a finding can assist athletes over time to realize that parents are there to help and not necessarily threaten or interfere with their independence.

\section{Elite sports participation.}

Although 6 studies examined the association between parent support and elite sport participation, the overall association was indeterminate. Three out of the six studies found that parental support positively influenced elite sports participation. Parents were deemed to play a significant role in introducing their children to elite sport (Baxter-Jones \& Maffulli, 2003). This finding was supported by Côté (1999) who examined the influence of family on talent development in sport. The study identified that parents offered further support across the subsequent stages of an athlete's career. Such supports include tangible (Finance, Time, Logistics) and emotional support (listening support during key set backs). This finding was supported by Pummell et al. (2008) when the entry career experiences of elite athletes were examined in a qualitative study.

In contrast three studies examined the negative association between parent support and elite sports participation. Le Bars et al. (2009) highlighted the negative role that parents can play in influencing drop out from elite sport. Athletes perceiving their parents, peers and coaches as less task involving and less task orientated were more likely to drop out from elite sport participation. This finding stresses the importance of the goal perspective that is promoted by parents in an athlete's environment. As highlighted by Hellstedt, J. C. 
(1990) parent pressure can play a key role in affecting a negative emotional response and lead to a withdrawal from sport.

\section{Athlete development.}

Several authors have discussed the important role that parents play in the development of talent in sport. (Bloom, 1985; Brustad, 1993; Hellstedt, 1987, 1995; Woolger \& Power, 1993). Five studies assessed the association of parent support with athlete development outcomes. The analysis generated an inconsistent association between the key variables of interest. Three studies completed in elite tennis between 2006 and 2010 analyzed a range of positive and negative parental support behaviors. Interestingly elite tennis coaches perceived the majority of parents as having a positive influence on their player's development. However, the respondents also felt that $36 \%$ of parents negatively influenced their child's development. Positive parental behaviors examined included providing logistical, financial, and social-emotional support, as well as tennis opportunities and unconditional love. Negative parent behaviors examined included overemphasizing winning, holding unrealistic expectations, and criticizing their child (Gould et al., 2006; Gould et al., 2008). Lauer, Gould, Roman and Pierce (2010) examined how specific parental behaviors exhibited changed as a function of the stage of athlete development. Analysis revealed a key trend across the stages of development. It was found that parents created a positive experience in the early stages of the athlete career however with mounting pressure in the middle years more conflicts occurred with the players and negative parenting manifested itself often in controlling and pushing behaviors. As a result parents were less involved in the senior elite years.

Evidence arising from a range of other sports indicated a positive association between parental support and athlete development outcomes. Pummell et al. (2008) identified a range of tangible, emotional and esteem supports provided by parents in event riding. This positive association was supported by Wylleman et al. (2003) in a multi sport study that revealed talented athletes perceive parental support to remain salient throughout development of their athlete career.

\section{Physical activity.}


The relationship between parental support and physical activity resulted in an inconsistent association across the three studies identified (Davison \& Jago, 2009; Keresztes, Piko, Pluhar \& Page, 2008; Wheeler, S., 2012). In an all female longitudinal study, Davison and Jago (2009) revealed an inconsistent relationship between parent support and physical activity. Results suggest that girls who maintained physical activity levels during adolescence had parents who had reported higher modeling of physical activity across all ages and sustained levels of logistical support. This is in contrast to consistently lower levels of parental modeling and declining level of logistical support for girls who did not maintain physical activity. The inconsistent association was further revealed by Keresztes et al. (2008) in a mixed subject study examining the social influences in sports activity amongst adolescents. The study revealed that over $85 \%$ of parents do not complete regular physical activity indicating a negative influence on physical activity levels. The study pointed to a key gender difference in the social influence by highlighting that adolescent female participation in sport was more likely to be influenced by peers in comparison to males.

In contrast, parents were shown to deploy a set of goals, practices and strategies designed to positively impact their children's participation in sport (Wheeler, S., 2012). It is suggested that these support behaviors are shaped by a parent's developmental history as well as their relationship with other parents.

\section{Athlete drop out.}

All three studies that examined the relationship between athlete drop out from sport indicated a positive association with parental support. Le Bars et al. (2009) completed two studies stressing the importance parental in creating a motivational climate that influences athlete persistence in sport. Findings indicate that a taskinvolving climate involving parental predicted athlete persistence in sport. Such a support climate corresponds with key support behaviors including challenging task choice and the promotion of greater effort and persistence regardless of perceived ability. Salguero et al. (2003) examined the reasons for drop out among 62 swimming drop outs. The study supports the previous association between coaching support and athlete drop out. The study determined that 'parental influence' was ranked twenty sixth amongst a list of 29 reasons for dropping out. 


\section{Peer support.}

Peer relationships have been shown to contribute to the quality of physical activity experiences of children and adolescence (Smith, 2003). Friendship and peer acceptance in the physical context have been linked with positive motivation - related outcomes (Smith, 2003, 2004; Weiss \& Struntz, 2004). Table 2 shows that the social support correlates and their directions relative to peer support. We identified five variables associated with the athlete peer relationship, including athlete motivation, elite sport participation, friendship quality, physical activity and drop out. These variables were all positively associated with athlete peer support. These associations are presented below in the order of the number of studies, which examined each correlate.

Furthermore findings from the review demonstrated a series of interactive links between the role of peers, parents and coaches. Ullrich-French and Smith (2009) investigated if parent and peer support affected player motivation and sport continuation in 148 players aged 10-14 years. Results showed that a combination of perceived mother relationship quality and perceived friendship quality predicted sports continuation. Riley and Smith (2011) demonstrated that higher perceptions of the athlete coach relationship positively impacted friendship quality and perceived per acceptance.

\section{Athlete motivation.}

Peer support was positively associated with athlete motivation as across all eight of the studies reviewed. Three studies examined the association between a single athlete peer relationship and athlete motivation (DeFreese \& Smith, 2013; Smith, Balaguer, \& Duda, 2006; Smith, Ullrich-French, Walker \& Hurley, 2006). Two studies examined peer support from a teammate perspective and a positive association between a positive perception of team mate support and athlete motivation was found (DeFreese, \& Smith, 2013; Smith et al., 2006). Smith et al. (2006) examined peer support through sports contextualized measures of perceived friendship quality and perceived peer acceptance. The authors found that sports participants who were in adaptive peer relationships were more likely to experience more adaptive motivation related responses in their sport. 
The athlete peer relationship in the context of other key support relationships with a coach or parent was examined in four studies (Riley \& Smith, 2011; Taylor, \& Bruner, 2012; Ullrich-French \& Smith 2006; UllrichFrench \& Smith, 2009). Both Riley and Smith, (2011) and Taylor and Bruner (2012) examined the combined positive influence of coach and peer support relationships on athlete motivation. While Ullrich-French and Smith, (2006) and Ullrich-French and Smith (2009) found a positive correlation between coach and peer support and its influence on athlete motivation.

Keegan et al. (2010) examined key support relationships involving coaches, peers and parents in a qualitative study. A positive association between these relationships and athlete motivation was found however the authors commented that it was almost impossible to establish any direct and exclusive correspondence between the behavior of a coach, parent, or peer and the effect on athlete motivation.

\section{Elite sport participation.}

Three studies reported positive association between peer support and elite sport participation. All three studies explored peer support from a teammate perspective and found that team support was positively associated with participation elite sport. In an all male study, Bruner et al. (2008) found that teammate support was critical during the entry into elite sport. Teammate support was also determined to play a key role in predicting athlete continuation in elite sport (Le Bars et al., 2009). In a longitudinal study lasting two years, the authors found that athlete perceptions of an ego involving motivational climate involving parents, coaches and peers increased in tandem with an increased intention of dropping out from elite sport.

In contrast, Côté, J. (1999) examined the role of an athlete's sibling in supporting an athlete's participation in elite sport. This qualitative study showed an inconsistent association between sibling support and elite athlete participation in sport. Older siblings acted as a role model of work ethic while younger siblings showed bitterness and jealousy towards their older sibling's achievement.

\section{Friendship quality.}

As cited by Carr, S. (2009), research completed to date has identified positive dimensions of children's friendship quality to be associated with a variety of variables such as increased satisfaction with peer relations, 
positive contextual emotional responses, peer acceptance, enhanced motivation, and enhanced achievement (e.g., Ladd, 1999; Newcomb \& Bagwell, 1995; Parker \& Asher, 1993; Parker \& Gottman, 1989). In contrast negative dimensions of friendship quality have been linked to maladaptive consequences such as negative attitudes, peer rejection, and behavioral difficulties (e.g., Coie \& Cillessen, 1993; Hartup, 1989). Four studies examined the association between peer support and friendship quality. A positive association between the variables of interest was found through three studies, which examined a measurement development for the quality of friendships in a youth sport population (Weiss \& Smith, 1999).

In contrast, a qualitative study completed by Weiss, Smith and Theeboom, (1996) reported an indeterminate association between perception of peer relationships and friendship quality. The study reported twelve positive friendship dimensions including: companionship, pleasant play/association, self-esteem enhancement, help and guidance, pro-social behavior, intimacy, loyalty, things in common, attractive personal qualities, emotional support, absence of conflicts, and conflict resolution. In contrast four negative friendship dimensions were reported including conflict, unattractive personal qualities, betrayal, and inaccessible. These conceptions of friendship were both similar and unique to friendship conceptions found in mainstream developmental research.

\section{Physical activity.}

As cited by Davison and Jago (2009), physical activity has been associated with positive physical (Jago, Wedderkopp \& Kirstensen, 2008; Leary, Ness \& Smith 2008; Ness, Leary \& Mattocks, 2007) and mental health (Schmalz, Deane, Birch \& Davison, 2007) among youth populations. Although there is some debate on gender differences concerning the rate of decline in physical activity amongst adolescents, there is considerable evidence that girls are less active than boys of all ages (Nader, Bradley, Houts \& O'Brien, 2008; Troiano, Berrigan, Dodd, Masse, Tilert \& McDowell, 2008).

Four studies reported a positive association between peer support and physical activity. Peer support was positively associated with adolescent physical activity levels in two studies focusing exclusively on female participation (Davison \& Jago, 2009; Voorhees et al., 2005). Voorhees et al. (2005) noted that that the 
frequency of physical activity with friends was an important correlate of physical activity levels in young female adolescents studied.

In mixed subject sample, Keresztes et al. (2008) found that in comparison to other significant others (parents and siblings), classmates generated the most significant social influence on physical activity levels. Smith (1999) examined the relationship between peer support and adolescent physical activity motivation. The study found a positive association between peer support and key affective responses towards physical activity motivation.

\section{Athlete drop out.}

The association between peer support and athlete drop out was examined in three studies. All three studies reported a positive correlation between peer support and disengagement from sport. Le Bars et al. (2009) completed a longitudinal study examining the association of parent, peer and coach related motivational climates to athlete persistence in elite sport. The authors reported a positive association between a coach, parent and peer induced ego-involving climate and drop out from elite sport. Salguero et al. (2003) examined drop out reasons in young competitive swimmers. Teammate related nonsupport was listed in 3 main drop out reasons and a lack of access to new friends was highlighted a reason for discontinuing sport participation.

\section{Discussion}

The present study aimed to provide a systematic review of social support in a youth sport context. Specifically, the review aims to provide a summary of sample characteristics, the key relationships of social support, and research designs employed up to March 2013. A total of 73 studies met the inclusion criteria and the results demonstrate that the study area has grown steadily over the past two decades. Researchers have used both qualitative and quantitative methods across both genders and various types of sports. The current review identified 16 variables relating to the quality of social support provided by coaches, parents and peers.

\section{Theories and Models}

Across all the studies, 34 employed a social theoretical approach followed by a motivational approach (19), developmental approach (10), cognitive approach (4), and behavioral approach (2). The findings indicate 
that the research area has expanded its theoretical base in accordance with recommendations contained in Jowett and Wylleman (2006). This theoretical diversity can shed light on relationship-related research questions from well-defined yet distinct angles.

The most significant feature of the social support studies (29) is best captured in the volume of recent publications (27) over the past 10 years. Only two studies (Baxter-Jones \& Maffulli, 2003; Hellstedt, 1990) were identified outside of this period. Rees and Hardy (2004) was first paper in the review to explore two principal models from the social psychology literature: the stress-buffering model and the main effect model (Cohen \& Wills, 1985). The stress-buffering model suggests that support is related to outcomes for those persons under stress while the main effects model proposes that social support has a benefit regardless if a person is under stress (Jowett \& Lavallee, 2007). These social support models signaled a new departure within the literature by offering researchers the opportunity to identify the conditions under which social support influences key outcomes. This review has identified that researchers have used these models to good effect bridging the link between social support and a range of key outcomes including performance (Rees \& Freeman, 2010; Rees \& Hardy, 2004); self confidence (Rees \& Freeman, 2007); perceived available support (Freeman, et al., 2012).

Researchers have identified the need for further evidence demonstrating which aspects of social support help and how (Rees \& Hardy, 2004). One such suggestion is that social support may help by moderating the effect of stress on key outcomes. This stress-buffering hypothesis is aligned with existing models concerning stress process, appraisal and coping. The most significant suggestion offered by Rees and Hardy (2004) is that social support leads to better coping with stress as coping is enhanced by the supportive actions of others. The authors highlight that social support be viewed as a multidimensional construct in order to address what type of supports are beneficial under what stress related conditions. One such future research direction suggests that researchers carefully match specific types of social support to specific stressors (Cutrona \& Russell, 1990). It is suggested that such an approach will aid understanding of which specific types of social support help to protect people from the harmful effects of specific types of stressors (Cutrona \& Russell, 1990). Such an approach 
presents a useful future research direction given the recent evidence concerning the definition of social support (Rees \& Hardy, 2000) and the use of recently validated measurement tools (e.g., PASS - Q; Freeman et al., 2011) designed to assess the functional aspects of social support.

Building on the previous research direction, several investigators have examined adolescent coping strategies in response to key stressors (Gould et al., 1996; Nicolas et al., 2011; Raedeke \& Smith, 2004; Sagar et al., 2010; Tamminen \& Holt, 2010, 2012). Results show how social influences on coping shape the development of adaptive or maladaptive coping responses. Identifying processes by which athletes learn about coping may provide practical information for parents, coaches, and sport practitioners to be better positioned to help young athletes develop effective coping strategies. By developing effective coping strategies, young athletes may be better equipped to manage the demands of competitive sport. However, research examining social influences on athlete coping is relatively unstudied (Tamminen \& Holt, 2012). The review points to a research direction, which may yield some positive impact concerning what types of supports are beneficial towards athlete coping and under what stress related conditions.

The support role concerning coaches, parents and teammates has also been recently explored through 2 contemporary theories of motivation: achievement goal theory (Ames, 1992, Nicholls, 1989) and selfdetermination theory (Deci \& Ryan, 1985, 2000). These theoretical approaches identify key dimensions of the sports environment (i.e. which support provider behaviors hold motivational significance) and also the motivational mechanisms via which support provided by others impacts upon how sport participants think, feel, and act. 13 studies identified in the review have explored this theoretical approach over the past 5 years alone. This theoretical approach has allowed researchers to explore the link between the behavior of support providers and key youth participation outcomes including burn-out (DeFreese \& Smith, 2013; Isoard-Gautheur, et al., 2013; Smith et al., 2010), drop out (Le Bars, et al., 2009), motivation (Adie \& Jowett, 2010; Felton \& Jowett, 2012; Kavussanu et al., 2011; Riley \& Smith, 2011; Smith et al., 2006; Taylor \& Bruner, 2012); fear of evaluation (Alfermann et al., 2013), and sport continuation (Ullrich-French \& Smith, 2009). 
Defreese and Smith (2013) highlights the need to continue the use and application of self-determination theory in order to grow the knowledge base concerning the psychosocial experiences of young people in sport. The authors highlight the need for researchers to draw upon broader social support literature that utilize existing conceptualizations or components of social support including the main effect models and the stress-buffering model. The authors identify the need for future research to address how specific aspects of social support (perceived and received support) and negative social interactions jointly shape psychological outcomes in sport.

\section{Sample Characteristics}

Research findings across the studies have indicated that athletes who are at different ages during their development present different support needs as a result of their individual stage of development (Côté, 1999; Lauer et al., 2010, Voorhees et al., 2005). Examining differences in age related variables might help practitioners to provide appropriate age related support for athletes at different stages of development. Moreover such age related differences may assist other support providers (e.g. parents) provide appropriate support as their child progresses through the various stages of talent development.

Gender differences have been identified in the review as a significant sample related characteristic. Gender related differences were identified across key variables including self-esteem (Douglas Coatsworth, \& Conroy, 2006), physical activity (Keresztes et al. 2008), parental modeling (Power \& Woolger, 1994), athlete motivation (Ullrich-French \& Smith, 2006), stress (Ullrich-French \& Smith, 2006). Examining gender differences across the coach, parent and peer support network may assist each support provider to provide the gender specific support that meets the needs of adolescent participants.

As highlighted by Alfermann et al. (2013), research in youth sport has largely been carried out in Western Countries. Few studies have addressed important variables for successful sports development in nonWestern countries and whether athletes from diverse cultures differ in those variables. It is clear from the review that there is more to be learned about key social support factors that influence the development of athletes from culturally diverse backgrounds. As highlighted by Park et al. (2013), investigating cultural 
diversity could assist in testing the generality and validity of existing knowledge and theories and lead to practical implications, such as providing suitable and appropriate support in applied work.

\section{Key Methodological Features}

In terms of research design, the review findings indicate that there is now a more diverse theoretical approach applied to the study of interpersonal relationships with five different theoretical approaches described in this review. The diversity of sport type and competition level demonstrated in the review show that the research field has taken into account the social context that impacts the interpersonal relationship under investigation. Although previous researchers have highlighted the need to adopt a lifespan approach, this review has identified a lack of longitudinal studies measuring key changes in an athlete's psychological network throughout their career. Moreover, the finding from the review also point to a lack of group level analysis across key relationships in an athlete's social network. For example an investigation of how coaches, parents and peers interact over time in a youth sport context would prove a useful contribution to the literature. The current review supports the previous calls for more longitudinal studies investigating the how athletes' interpersonal relationships with coaches, parents, siblings, partners, and other significant others, evolve before, during, and after their sport career (Wylleman \& Lavallee, 2004).

Based on the review findings, several research directions can be identified with regard to research design. For example the majority of researchers have used retrospective data collection methods, which may have negatively affected the data recall process. Employing a prospective longitudinal designs to study how an athlete's social support network evolve before, during and after their sports career would allow researchers to examine dynamic interpersonal support processes over time. Therefore, more prospective longitudinal studies are required in the study area.

Numerous authors (e.g., Felton \& Jowett, 2012) have discussed the need for intervention strategies to target the provision of certain social support behaviors towards youth athletes. However, only one study (Douglas Coatsworth \& Conroy, 2006) has used an intervention-based approach to assess the effectiveness of a specific intervention or training program for providing effective support to youth athletes. Further research is 
required into whether specific psychological interventions can assist practitioners in facilitating the development of more effective forms of social supports across the varied social actors in an athlete's psychological network.

Nearly half of the studies in the review used different social support related questionnaires (13), which reflect the varied conceptualization and measurement of social support. Previous authors have commented on the lack of consensus regarding the nature and definition of social support constructs (Rees \& Hardy, 2000). The review indicates that there is greater clarity concerning the definition of social support in sport (Rees \& Hardy, 2000). This has lead to the development of recently validated measurement tools (e.g. PASS - Q; Freeman et al., 2011). The development of such measures that accurately assess specific support constructs will help to answer theoretically important questions, such as which types of support are beneficial and under what conditions (Cohen et al., 2000).

\section{Practical Applications}

Several practical implications for sport psychologists, advisors working with athletes and a range social support providers emerged from the present review. Coaches, parents and peers have been shown to positively influence a range of factors impacting the youth development in sport. However results from the two longitudinal studies (Davison \& Jago, 2009; Le Bars et al., 2009) contained in the review indicate that the social support profile arising from key social support providers dynamically changed and had a negative influence on participation patterns in both elite sport and physical activity. Therefore to assist athletes in sustaining long terms adherence to sport participation at the sub elite and elite level, practitioners need to be cognizant of the type of support and the changing patterns of support emerging within an athlete's psychological network.

Researchers (Freeman et al., 2011; Rees, et al., 2012) have identified individuals who perceive their relationships as supportive have been shown to experience a range of favorable outcomes. In examining perceiver, target and relational components of perceived coach support, the review indicates that the relational component plays the most significant role in determining perception around coach supportiveness or 
unsupportiveness (Rees et al., 2012). Such a finding may inform researchers and applied practitioners as they consider the match between athletes and coaches in order to ensure that supportive relationships are formed. Furthermore this optimal matching approach can also allow practitioners to carefully match specific types of social support to specific stressors (Cutrona \& Russell, 1990). Such an approach can aid understanding of which specific types of social support help protect people from the harmful effects of specific types of stressors (Cutrona \& Russell, 1990).

This review has several limitations. Only English language studies were included in the review. During the search process two foreign studies [one Spanish (Carratala, Gutierriez, Guzman, and Pablos, 2011) and one Norwegian (Railo, 1980)] were excluded. The exclusion of these non-English studies might influence sample characteristics (e.g. location of study) and lead to the omission of potential correlates that may be culturally significant. A further limitation of the review relates to the omission of some correlates due to limited space and the review guidelines adopted (Goodger et al., 2007; Park, et al., 2012; Sallis et al., 2000). These correlates include the following in the coach support provider category: interpersonal conflict (Jowett, 2008, 2009); athlete coping (Nicolas et al., 2011); athlete self concept (Jowett \& Cramer, 2010); athlete self- esteem (Douglas Coatsworth \& Conroy, 2006); fear of failure (Sagar et al., 2010); team cohesion (Tamminen \& Holt, 2012); well being (Felton \& Jowett, 2013); commitment (Weiss, Kimmel, \& Smith, 2001); sport achievement (Nicolas et al., 2011); athlete performance anxiety (Smith et al., 1995). Correlates relating to parent support include child enthusiasm (Power \& Woolger, 1994), youth sport friendship (Carr, 2009), fear of failure (Sagar et al., 2010); burnout (Gould et al., 1996), well being (Felton \& Jowett, 2013), and athlete self-concept (Jowett \& Cramer, 2010). The correlates relating to peer support included the following: burnout (Defreese \& Smith, 2013; Smith et al. 2010); sport participation (Ullrich - French \& Smith, 2006, 2009); and conflict resolution (Holt et al., 2008). As a result correlates with fewer than three supporting studies were either grouped into similar categories or not included in the summary table. Such omissions might preclude such a review from suggesting directions for examining similar correlates of interest. 


\section{Conclusion}

Research into the area of support relationships in youth sport has developed significantly over the past decade. However, despite encouragement for athletes to use social support and recommendations for research (Jowett \& Lavallee, 2007), the research area remained comparatively underdeveloped up to recently. A proliferation of research over the past 10 years has contributed a greater understanding of key interpersonal relationships in sport exercise and the exercise settings. New levels of understanding have emerged concerning the various types of support (informational, esteem, emotional, tangible) offered in an athlete's social network. Coaches were identified as the most prevalent provider of support in a youth sport context through offering athletes unique forms of tangible, informational, emotional and esteem support. Moreover, the combined effect of coach, parent and peer support have been shown to play a significant role in shaping youth sport experiences both from a positive (athlete motivation levels, elite sport participation) and negative perspective (drop out)

This systematic review focused on key support relationships in a youth sport context and reported the status of the research area whilst highlighting limitations in the research field. Moreover, the present review suggests several future directions including research design (e.g., use of longitudinal study designs), sample characteristics (e.g., age and gender related differences), correlates (e.g., drop out) and practical implications e.g., optimal support matching. 


\section{References}

Adie, J. W., \& Jowett, S. (2010). Meta-perceptions of the coach-athlete relationship, achievement goals, and intrinsic motivation among sport participants. Journal of Applied Social Psychology, 40(11), 2750-2773.

Alfermann, D. (1995, July). Career transitions of elite athletes: Drop-out and retirement. Paper presented at the 9th European Congress of Sport Psychology, Brussels, Belgium.

Alfermann, D., Geisler, G., \& Okade, Y. (2013). Goal orientation, evaluative fear, and perceived coach behavior among competitive youth swimmers in Germany and Japan. Psychology of Sport and Exercise, 14(3), 307-315.

Ames, C. (1992). Achievement goals and adaptive motivational patterns: The role of the environment. In G.C. Roberts (Ed.), Motivation in sport and exercise (pp. 161-176). Champaign, IL: Human Kinetics.

Baxter-Jones, A. D. G., \& Maffulli, N. (2003). Parental influence on sport participation in elite young athletes. Journal of Sports Medicine and Physical Fitness, 43(2), 250-255.

Bianco, T., \& Eklund, R.C. (2001). Conceptual considerations for social support research in sport and exercise settings: The case of sport injury. Journal of Sport \& Exercise Psychology, 23, 85-107.

Bloom, B.S., (1985). Developing talent in young people. New York: Ballantine.

Bruner, M. W., Munroe-Chandler, K. J., \& Spink, K. S. (2008). Entry into elite sport: A preliminary investigation into the transition experiences of rookie athletes. Journal of Applied Sport Psychology, 20(2), 236-252.

Brustad, R.J. (1993). Who will go out and play? Parental and psychological influences on children's attraction to physical activity. Pediatric Science, 5, 210-223.

Carr, S. (2009). Adolescent-parent attachment characteristics and quality of youth sport friendship. Psychology of Sport and Exercise, 10, 653-661

Carratala, V., Gutierrez, M., Guzman, J.F., \& Pablos, C., (2011). Youth sport environment perceived by athletes, parents, coaches and managers. Revista de Psicologia del Deporte, 20(2), 337-352. 
Cohen, S., Gottlieb, B.H., \& Underwood, L.G. (2000). Social relationships and health. In S. Cohen, L.G. Underwood, \& B.H. Gottlieb (Eds.), Social support measurement and intervention: A guide for health and social scientists (pp. 3-25). New York: Oxford University Press.

Cohen, S., \& Wills, T.A. (1985). Stress, social support and the buffering hypothesis. Psychological Bulletin, 98, 310-357.

Coie, I. D., \& Cillessen, A. H. N. (1993). Peer rejection: Origins and effects on children's development. Current Directions, 2, 89-92.

Côté, J. (1999). The influence of the family in the development of talent in sport. The Sport Psychologist, 13(4), 395-417.

Côté, J., \& Fraser-Thomas, J. (2007). Youth involvement in sport. In P. Crocker (Ed.), Sport psychology: A Canadian perspective. (pp. 270-298). Toronto, Canada: Pearson.

Craig, P., Dieppe, P., Macintyre, S., Michie, S., Nazareth, I., \& Petticrew, M. (2008). Developing and evaluating complex interventions: The new Medical Research Council guide. British Medical Journal, 337, a1655. doi:10.1136/bmj.a1655

Csikszentmihalyi, M., Rathunde, K., \& Whalen, S. (1993). Talented teenagers: The roots of success and failure. New York: Cambridge University Press.

Cutrona, C.E., \& Russel, D.W. (1990). Type of social support and specific stress: Towards a theory of optimal matching. In B. R. Sarason, I.G. Sarason \& G. R. Pierce (Eds). Social support: An interactional view (pp 319 - 366). New York: Wiley.

Davison, K. K., \& Jago, R. (2009). Change in parent and peer support across ages 9 to $15 \mathrm{yr}$ and adolescent girls' physical activity. Medicine and Science in Sports and Exercise, 41(9), 1816-1825.

Deci, E. L., \& Ryan, R. M. (1985). Intrinsic motivation and self-determined human behavior. New York: Plenum Press.

Deci, E. L., \& Ryan, R. M. (2000). The "what" and "why” of goal pursuits: Human needs and the selfdetermination of behavior. Psychological Enquiry, 11, 227-268. 
DeFreese, J. D., \& Smith, A. L. (2013). Teammate social support, burnout, and self-determined motivation in collegiate athletes. Psychology of Sport and Exercise, 14(2), 258-265.

Dorsch, T. E., Smith, A. L., \& McDonough, M. H. (2009). Parents' perceptions of child-to-parent socialization in organized youth sport. Journal of Sport \& Exercise Psychology, 31(4), 444-468.

Douglas Coatsworth, J., \& Conroy, D. E. (2006). Enhancing the self-esteem of youth swimmers through coach training: Gender and age effects. Psychology of Sport and Exercise, 7(2), 173-192.

Durand-Bush, N., Salmela, J.H., Thompson, K.A. (2004). Le role joue' par les parents dans le developpement et le maintien de la performance athletique experte. STAPS, 64, 15-38.

Elliot, A. J., \& McGregor, H. A. (2001). A 2x2 achievement goal framework. Journal of Personality and Social Psychology, 80, 501-519.

Felton, L., \& Jowett, S. (2012). "What do coaches do" and "how do they relate": Their effects on athletes' psychological needs and functioning. Scandinavian Journal of Medicine and Science in Sports, doi: 10.1111/sms.12029

Felton, L., \& Jowett, S. (2012). The mediating role of social environmental factors in the associations between attachment styles and basic needs satisfaction. Journal of Sports Sciences, 1- 11.

Felton, L., \& Jowett, S. (2013). Attachment and well-being: The mediating effects of psychological needs satisfaction within the coach-athlete and parent-athlete relational contexts. Psychology of Sport and Exercise, 14(1), 57-65.

Fredricks, J. A., \& Eccles, J. S. (2006). Extracurricular involvement and adolescent adjustment: Impact of duration, number of activities, and breadth of participation. Applied Developmental Science, 10(3), $132-146$.

Freeman, P., Coffee, P., \& Rees, T. (2011). The PASS-Q: The perceived available support in sport questionnaire. Journal of Sport \& Exercise Psychology, 33(1), 54-74.

Fry, M. D., \& Gano-Overway, L. A. (2010). Exploring the contribution of the caring climate to the youth sports experience. Journal of Applied Sport Psychology, 22, 294-304. 
Goodger, K., Gorely, T., Lavallee, D., \& Harwood, C. (2007). Burnout in sport: A systematic review. The Sport Psychologist, 21, 127-151.

Gould D, Dieffenbach K., \& Moffett A. (2002). Psychological characteristics and their development in Olympic champions. Journal of Applied Sport Psychology, 14:172-204.

Gould, D., Eklund, R., Petlichkoff. L., et al (1991). Psychological predictors of state anxiety and performance in age-group wrestlers. Pediatric Exercise Science. 3:198-208.

Gould, D., Flett, R., \& Lauer, L. (2012). The relationship between psychosocial developmental and the sports climate experienced by underserved youth. Psychology of Sport and Exercise, 13(1), 80-87.

Gould, D., Lauer, L., Rolo, C., Jannes, C., \& Pennisi, N. (2006). Understanding the role parents play in tennis success: A national survey of junior tennis coaches. British Journal of Sports Medicine, 40(7), 632-636.

Gould, D., Lauer, L., Rolo, C., Jannes, C., \& Pennisi, N. (2008). The role of parents in tennis success: Focus group interviews with junior coaches. The Sport Psychologist, 22(1), 18-37.

Gould, D., Tuffey, S., Udry, E., \& Loehr, J. (1996). Burnout in competitive junior tennis players: I. A quantitative psychological assessment. The Sport Psychologist, 10(4), 322-340.

Greendorfer, S.L. (2002). Socialization process and sport behavior. In T. Horn (Ed.), Advances in sport psychology (pp. 377-401). Champaign, IL: Human Kinetics.

Hartup, W. W. (1989). Behavioral manifestations of children's friendships. In T. J. Bemdt, \& G. W. Ladd (Eds.), Peer relationships in child development (pp. 46-70). New York: Wiley.

Hellstedt, J. C. (1990). Early adolescent perceptions of parental pressure in the sport environment. Journal of Sport Behavior, 13(3), 135.

Hellstedt, J.C. (1987). The coach /parent /athlete relationship. The Sport Psychologist. 1, 151- 160.

Hellstedt, J.C. (1995). Invisible players: A family system model. In S.M. Murphy, Sport psychology interventions (pp.117-146). Champaign, IL: Human Kinetics.

Hollander, D., Meyers, D., \& LeUnes, A. (1995). Psychological factors associated with overtraining: Implications for youth sport coaches. Journal of Sport Behavior, 18(1), 3-20. 
Holt, N.L., \& Hoar, S.D. (2006). The multidimensional construct of social support. In S. Hanton \& S.D. Mellalieu (Eds.), Literature reviews in sport psychology (pp. 199-225). Hauppauge, NY: Nova Science.

Holt, N. L., Black, D. E., Tamminen, K. A., Fox, K. R., \& Mandlgo, J. L. (2008). Levels of social complexity and dimensions of peer experiences in youth sport. Journal of Sport \& Exercise Psychology, 30(4), 411431.

Iso-Ahola, S. E. (1995). Intrapersonal and interpersonal factors in athletics performance. Scandinavian Journal of Medicine and Science in Sports, 5, 191- 199.

Jago, R., Wedderkopp, N., Kristensen, P.L., Moller, N.,C., Anderson, L.B., Cooper, A.R., \& Froberg, K. (2008). Six year change in youth physical activity and effect on fasting insulin and HOMA-IR. American Journal of Preventitive Medicine. 35 (6), 554 - 560.

Jowett, S. (2006). Interpersonal and structural features of Greek coach-athlete dyads performing in individual sports. Journal of Applied Sport Psychology, 18(1), 69-81.

Jowett, S. (2008). Outgrowing the familial coach-athlete relationship. International Journal of Sport Psychology, 39(1), 20-40.

Jowett, S. (2009). Validating coach-athlete relationship measures with the nomological network. Measurement in Physical Education and Exercise Science, 13(1), 34-51.

Jowett, S., \& Cramer, D. (2010). The prediction of young athletes' physical self from perceptions of relationships with parents and coaches. Psychology of Sport and Exercise, 11(2), 140-147.

Jowett, S., \& Lavallee, D. (2007). Social psychology in sport. Champaign, IL: Human Kinetics

Jowett, S., \& Poczwardowski, A. (2007). Understanding the coach-athlete relationship. In S. Jowett \& D. Lavallee (Eds.), Social psychology in sport (pp. 3-14). Champaign, IL: Human Kinetics.

Jowett, S., \& Timson-Katchis, M. (2005). Social networks in sport: Parental influence on the coach-athlete relationship. Sport Psychologist, 19(3), 267-287.

Jowett, S., \&, Wylleman, P. (2006). Interpersonal relationships in sport and exercise settings: Crossing the chasm. Psychology of Sport and Exercise, 7, 119 - 123. 
Kavussanu, M., White, S. A., Jowett, S., \& England, S. (2011). Elite and non-elite male footballers differ in goal orientation and perceptions of parental climate. International Journal of Sport and Exercise Psychology, 9(3), 284-290.

Keegan, R., Spray, C., Harwood, C., \& Lavallee, D. (2010). The motivational atmosphere in youth sport: Coach, parent, and peer influences on motivation in specializing sport participants. Journal of Applied Sport Psychology, 22(1), 87-105.

Keresztes, N., Piko, B. F., Pluhar, Z. F., \& Page, R. M. (2008). Social influences in sports activity among adolescents. Journal of the Royal Society for the Promotion of Health, 128(1), 21-25.

Ladd, G. W. (1999). Peer relationships and social competence during early and middle childhood. Annual Review of Psychology: 50, 333-359.

Lafrenière, M. A. K., Jowett, S., Vallerand, R. J., \& Carbonneau, N. (2011). Passion for coaching and the quality of the coach-athlete relationship: The mediating role of coaching behaviors. Psychology of Sport and Exercise, 12(2), 144-152.

Lakey, B. (2010). Social support: Basic research and new strategies for intervention. In J. E. Maddux \& J. P. Tangney (Eds.) Social Psychological Foundations of Clinical Psychology (pp. 177 - 194). NY: Guilford.

Lauer, L., Gould, D., Roman, N., \& Pierce, M. (2010). Parental behaviors that affect junior tennis player development. Psychology of Sport and Exercise, 11(6), 487-496.

Lavallee, D., \& Wylleman., P. (2000, 2007). Career transitions in sport: International perspectives. Morgantown, WV, USA. Fitness Information Technology

Leary, S., Ness, D. A. R., Smith, G. D. (2008). Physical activity and blood pressure in children: Findings from a population based study. Hyperttension. 51: $92-98$.

Le Bars, H., Gernigon, C., \& Ninot, G. (2009). Personal and contextual determinants of elite young athletes' persistence or dropping out over time. Scandinavian Journal of Medicine and Science in Sports, 19(2), 274-285. 
Lorimer, R., \& Jowett, S. (2009). Empathic accuracy, meta-perspective, and satisfaction in the coach-athlete relationship. Journal of Applied Sport Psychology, 21(2), 201-212.

Lubans, D. R., Morgan, P. J., \& McCormack, A. (2011). Adolescents and school sport: The relationship between beliefs, social support and physical self-perception. Physical Education and Sport Pedagogy, $16(3), 237-250$.

Nadar, P.R., Bradley, R.H., Houts, R.M., McRitchie, S, L., \& O’Brien, M. (2008). Moderate to vigorous physical actvity from the ages of 12 to 15 years old. JAMA. I300 (3), $295-305$.

Ness, A. R., Leary S. D., \& Mattocks, C. (2007). Objectively measured physical activity and fat mass in a large cohort of children. PLos Med. 4:e97.

Newcomb, A. F., \& Bagwell, C. L. (1995). Children's friendship relations: A meta analytic review. Psychological Bulletin. 117, 306-347.

Nicholls, J. G. (1989). The competitive ethos and democratic education. Cambridge, MA: Harvard University Press.

Nicolas, M., Gaudreau, P., \& Franche, V. (2011). Perception of coaching behaviors, coping, and achievement in a sport competition. Journal of Sport \& Exercise Psychology, 33(3), 460-468.

Ntoumanis, N., Vazou, S., Duda, J. (2007). Peer-created motivational climate. In S. Jowett, \& D. Lavallee (Eds.) Social psychology in sport (pp. 131 - 143). Champaign, IL, USA. Human Kinetics

Park, S., Lavallee, D., \& Tod, D. (2012). Athletes' career transition out of sport: A systematic review. International Review of Sport and Exercise Psychology. 1-32

Parker, J. G., \& Asher, S. R. (1993). Friendship and friendship quality in middle childhood: links with peer group acceptance and feelings of loneliness and social dissatisfaction. Developmental Psychology. 29, $611-621$.

Parker, J. G., \& Gottman, J. M. (1989). Social and emotional development in a relational context: friendship interaction from early childhood to adolescence. In T. J. Bemdt, \& G. W. Ladd (Eds.), Peer relationships in child development (pp. 95-131). New York: Wiley. 
Pierce, G. R., Sarason, I. G., Sarason, B. R., Solky-Butzel, J. A., \& Nagle, L. C. (1997). Assessing the quality of personal relationships. Journal of Social and Personal Relationships, 14, 339-356.

Philippe, R. A., Sagar, S. S., Huguet, S., Paquet, Y., \& Jowett, S. (2011). From teacher to friend: The evolving nature of the coach-athlete relationship. International Journal of Sport Psychology, 42(1), 1-23.

Power, T. G., \& Woolger, C. (1994). Parenting practices and age-group swimming: A correlational study. Research Quarterly for Exercise and Sport, 65(1), 59-66.

Pummell, B., Harwood, C., \& Lavallee, D. (2008). Jumping to the next level: A qualitative examination of within-career transition in adolescent event riders. Psychology of Sport and Exercise, 9(4), 427-447.

Raedeke, T. D. (1997). Is athlete burnout more than just stress? A sport commitment perspective. Journal of Sport \& Exercise Psychology, 19, 396-417.

Raedeke, T. D., \& Smith, A. L. (2001). Development and preliminary validation of an athlete burnout measure. Journal of Sport \& Exercise Psychology, 23, 281-306.

Raedeke, T. D., \& Smith, A. L. (2009). The Athlete Burnout Questionnaire manual. Morgantown, WV: West Virginia University.

Raedeke, T. D., \& Smith, A. L. (2004). Coping resources and athlete burnout: An examination of stress mediated and moderation hypotheses. Journal of Sport and Exercise Psychology, 26(4), 525-541.

Railo, W.S., (1980). The relation of sport in childhood and youth to psychosocial health. Tidsskrift for den Norske laegeforening, 100(12 B). 799-806+878.

Rees, T. (2007). Influence of social support on athletes. In S. Jowett \& D. Lavallee (Eds.), Social psychology in sport (pp. 223-231). Champaign, IL: Human Kinetics.

Rees, T., \& Freeman, P. (2007). The effects of perceived and received support on self-confidence. Journal of Sports Sciences, 25(9), 1057-1065.

Rees, T., \& Freeman, P. (2010). Social support and performance in a golf-putting experiment. The Sport Psychologist, 24(3), 333-348. 
Rees, T., Freeman, P., Bell, S., \& Bunney, R. (2012). Three generalizability studies of the components of perceived coach support. Journal of Sport \& Exercise Psychology, 34(2), 238-251.

Rees, T., \& Hardy, L. (2000). An investigation of the social support experiences of high-level sport performers. The Sport Psychologist, 14, 327-347.

Rees, T., \& Hardy, L. (2004). Matching social support with stressors: Effects on factors underlying performance in tennis. Psychology of Sport and Exercise, 5(3), 319-337.

Rees, T., Hardy, L., \& Evans, L. (2007). Construct validity of the social support survey in sport. Psychology of Sport and Exercise, 8(3), 355-368.

Rhind, D., \& Jowett, S. (2012). Development of the coach-athlete relationship maintenance questionnaire (CARM-Q). International Journal of Sports Science and Coaching, 7(1), 121-137.

Rhind, D. J. A., \& Jowett, S. (2011). Linking maintenance strategies to the quality of coach-athlete relationships. International Journal of Sport Psychology, 42(1), 55-68.

Riley, A., \& Smith, A. L. (2011). Perceived coach-athlete and peer relationships of young athletes and selfdetermined motivation for sport. International Journal of Sport Psychology, 42(1), 115-133.

Sagar, S. S., Busch, B. K., \& Jowett, S. (2010). Success and failure, fear of failure, and coping responses of adolescent academy football players. Journal of Applied Sport Psychology, 22(2), 213-230.

Salguero, A., Gonzalez-Boto, R., Tuero, C., \& Marquez, S. (2003). Identification of dropout reasons in young competitive swimmers. Journal of Sports Medicine and Physical Fitness, 43(4), 530-534.

Sallis, J.F., Prochaska, J.J., \& Taylor, A.C. (2000). A review of correlates of physical activity of children and adolescents. Medicine and Science in Sport and Exercise, 32, 963-975. doi: 0195-9131/00/3205-0963/0

Salmela, J.H., Young, B.W., Kallio, J. (2000; 2007). Within-career transitions of the athlete-coach-parent triad. In D. Lavallee, \& P. Wylleman (Eds.) Career transitions in sport: International perspectives (pp. 181194). Morgantown, WV, USA. Fitness Information Technology

Santrock, J. W. (2010). Life-span development (13th edn.). New York: McGraw-Hill. 
Scanlan, T., Lewthwaite, R. (1984). Social psychological aspects of competition for male youth sport participants. I. Predictors of competitive stress. Journal of Sport Psychology. 6:208-26.

Schlossberg, N. (1981). A model for analyzing human adaptation to transition. The Counseling Psychologist, $9(2), 2-18$.

Schmalz, D. L., Deane, G.D., Birch, L.L., Davison, K.K. (2007). A longitudinal assessment of the links between physical activity and self esteem in early adolescent non Hispanic females. Journal of Adolescent Health. 41: $559-565$.

Shumaker, S.A., \& Brownell, A. (1984). Toward a theory of social support: Closing conceptual gaps. Journal of Social Issues, 40, 11-36.

Skinner, E. A., \& Zimmer-Gembeck, M. J. (2007). The development of coping. Annual Review of Psychology, $58,119-144$.

Smith, A. L. (2003). Peer relationships in physical activity contexts: A road less travelled in youth sport and exercise psychology research. Psychology of Sport and Exercise. 4, 25 - 39.

Smith, A. L. (2007). Youth peer relationships in sport. In S. Jowett, \& D. Lavallee (Eds.) Social psychology in sport (pp. 41 - 45). Champaign, IL, USA. Human Kinetics

Smith, A. L. (1999). Perceptions of peer relationships and physical activity participation in early adolescence. Journal of Sport \& Exercise Psychology, 21(4), 329-350.

Smith, A. L., Balaguer, I., \& Duda, J. L. (2006). Goal orientation profile differences on perceived motivational climate, perceived peer relationships, and motivation-related responses of youth athletes. Journal of Sports Sciences, 24(12), 1315-1327.

Smith, D., \& Bar - Eli, M. (2007). Essential readings in sport and exercise psychology. Champaign, IL, USA. Human Kinetics

Smith, A. L., Gustafsson, H., \& Hassmén, P. (2010). Peer motivational climate and burnout perceptions of adolescent athletes. Psychology of Sport and Exercise, 11(6), 453-460. 
Smith, A.L., \& McDonough, M.H. (2008). Peers. In A.L. Smith \& S.J.H. Biddle (Eds.), Youth physical activity and sedentary behavior (pp. 295-320). Champaign, IL: Human Kinetics.

Smith, A. L., Ullrich-French, S., Walker II, E., \& Hurley, K. S. (2006). Peer relationship profiles and motivation in youth sport. Journal of Sport and Exercise Psychology, 28(3), 362-382.

Smith, R. E., Smoll, F. L., \& Barnett N, P. (1995). Reduction of children's sport anxiety through social support and stress-reduction training for coaches. Journal of Applied Developmental Psychology, 16, 125-142.

Smith, R. E., Smoll, F. L., \& Cumming, S. P. (2007). Effects of a motivational climate intervention for coaches on young athletes' sport performance anxiety. Journal of Sport \& Exercise Psychology, 29, 39-59.

Smith, R. E., Smoll, F. L., \& Curtis B. (2007). Coach effectiveness training: A cognitive-behavioral approach to enhancing relationship skills in youth sport coaches. In D. Smith, \& M. Bar - Eli (2007). Essential readings in sport and exercise psychology (pp. 393 - 400). Champaign, IL, USA. Human Kinetics

Strachan, L., Côté, J., \& Deakin, J. (2009). "Specializes" versus "samplers" in youth sport: Comparing experiences and outcomes. The Sport Psychologist, 23(1), 77-92.

Strachan, L., Côté, J., \& Deakin, J. (2009). An evaluation of personal and contextual factors in competitive youth sport. Journal of Applied Sport Psychology, 21(3), 340-355.

Tamminen, K. A., \& Holt, N. L. (2012). Adolescent athletes' learning about coping and the roles of parents and coaches. Psychology of Sport and Exercise, 13(1), 69-79.

Taylor, I. M., \& Bruner, M. W. (2012). The social environment and developmental experiences in elite youth soccer. Psychology of Sport and Exercise, 13(4), 390-396.

Troiano, R. P., Berrigan, D., Dodd, K.W., Masse, L.C., Tilert, T., \& McDowell, M. (2008). Physical activity in the United States measured by accelerometer. Medicine Science Sports Exercise. 40 (1), 81 -188.

Ullrich-French, S., \& Smith, A. L. (2006). Perceptions of relationships with parents and peers in youth sport: Independent and combined prediction of motivational outcomes. Psychology of Sport and Exercise, 7(2), 193-214. 
Ullrich-French, S., \& Smith, A. L. (2009). Social and motivational predictors of continued youth sport participation. Psychology of Sport and Exercise, 10(1), 87-95.

Voorhees, C. C., Murray, D., Welk, G., Birnbaum, A., Ribisl, K. M., Johnson, C. C., \& Jobe, J. B. (2005). The role of peer social network factors and physical activity in adolescent girls. American Journal of Health Behavior, 29(2), 183-190.

Weiner, B. (1992). Human motivation: Metaphors, theories, and research. Newbury Park, CA: Sage

Weiss, M. R., \& Fretwell, S. D. (2005). The parent-coach/child-athlete relationship in youth sport: Cordial, contentious, or conundrum? Research Quarterly for Exercise and Sport, 76(3), 286-305.

Weiss, M. R., Kimmel, L. A., \& Smith, A. L. (2001). Determinants of sport commitment among junior tennis players: Enjoyment as a mediating variable. Pediatric Exercise Science, 13(2), 131-144.

Weiss, M. R., \& Smith, A. L. (1999). Quality of youth sport friendships: Measurement development and validation. Journal of Sport \& Exercise Psychology, 21(2), 145-166.

Weiss, M. R., Smith, A. L., \& Theeboom, M. (1996). "That's what friends are for": Children's and teenagers' perceptions of peer relationships in the sport domain. Journal of Sport \& Exercise Psychology, 18(4), 347-379.

Weiss, M. R., \& Stuntz, C. P. (2004). A little friendly competition: Peer relationships and psychosocial development in youth sport and physical activity contexts. In M.R. Weiss (Ed.) Developmental sport and exercise psychology: A lifespan perspective (pp. 165 - 196). Morgantown, WV. Fitness Information Tecnology

Weis, M. R., \& Wiese-Bjornstal, D.M. (2009). Promoting positive youth development through physical activity. Research Digest. President's Council on Physical Fitness and Sports. Washington, DC, USA

Wheeler, S. (2012). The significance of family culture for sports participation. International Review for the Sociology of Sport, 47(2), 235-252.

White, S.A. (2007). Parent-created motivational climate. In S. Jowett, \& D. Lavallee (Eds.). Social psychology in sport (pp. 131 - 143). Champaign, IL, USA. Human Kinetics 
Woolger, C., \& Power, T.G. (1993). Parent and sport socialization: Views from the achievement literature. Journal of Sport Behavior, 16(3), 171-189.

Wylleman, P. (2000). Interpersonal relationships in sport: Unchartered territory in sport Ppychology Research. International Journal of Sport Psychology, 31, 555-572.

Wylleman, P., De Knop, P., Ewing, M.E., Cumming S.P. (2000, 2007). Transitions in youth sport. A developmental perspective on parental involvement. In D. Lavallee, \& P. Wylleman. (Eds.) Career transitions in sport: International perspectives (pp. 143-160) Morgantown, WV, USA. Fitness Information Technology

Wylleman, P., De Knop, P., Sloore H., Vanden Auweele, Y., \& Ewing, M.,. (2003). Talented athlete perceptions of the athlete coach parent relationships. Kinesiolgia Slovenica, 2, 59-69.

Wylleman, P., De Knop, P., Verdet, M.C, Cecic - Erpic, S., (2007). Parenting and career transitions of elite athletes. In S. Jowett, \& D. Lavallee (Eds.) Social psychology in sport (pp. 233 - 247). Champaign, IL, USA. Human Kinetics

Wylleman, P., \& Lavallee, D. (2004). A developmental perspective on transitions faced by athletes. In M. Weiss (Ed.), Developmental sport and exercise psychology: A lifespan perspective (pp. 507-527). Morgantown, WV: FIT. 
Table 1. Research Designs and Sample Characteristics

\section{Study Characteristics Reference Number}

Samples

$\mathbf{K}$

\section{Design}

Quantitative

$1,2,5,7,8,10,11,12,13,14,15,16,17,19,20,22,23,25,26,27$,

Qualitative $52,54,55,56,57,58,59,60,62,63,64,65,67,68,69,70,73$

Combined

53

Longitudinal

7,35

Cross Sectional

$1,2,3,4,5,6,8,9,10,11,12,13,14,15,16,17,18,19,20,21,22$, $23,24,25,26,27,28,29,30,31,32,33,34,36,37,38,39,40,41$, $42,43,44,45,46,47,48,49,50,51,52,53,54,55,56,57,58,59$, $60,61,62,63,64,65,66,67,68,69,70,71,72,73$

\section{Data Collection}

Qualitative

$3,4,6,9,18,21,24,28,30,33,36,39,41,53,61,66,71,72$

Quantitative (Social Support)

\section{$50,51,52,58,63,64,65,68,69,70,73$}

Quantitative (Psychology)

$2,5,7,10,13,16,19,22,29,32,34,35,37,42,53,54,55,56,57, \quad 22$

Quantitative (Other)

$$
17,20,31,67
$$

\section{Theoretical Approach}

Cognitive

Behavioral

$6,19,38,42$

32,67

1

Motivational

$1,2,8,10,11,16,22,29,34,35,40,52,55,56,57,58,62,63,64$,

Social 66

Developmental

$3,7,9$,

$9,14,15,17,18,20,21,23,24,25,26,27,28,31,36,37,39$, $43,44,45,46,47,48,49,50,51,53,60,61,65,72,73$

Not Evident 


\section{Support Provider Relationship - Single Relational Level}

Athlete - Coach

Athlete - Parent

$1,2,10,11,23,24,25,26,32,36,38,39,45,46,47,50,51,66$

18

Athlete - Peer

$3,5,9,17,18,20,24,29,33,40,66,72,73$

13

Athlete-Peer

$8,21,55,56,58,65,68,69,70,71$

10

Support Provider Relationship - Multi Relational Level

Athlete - Coach - Parent -

$30,34,35,41,73$

Peer

Athlete - Coach - Parent

$12,13,24,27,28,61,66,73$

$5,7,63,72$

Athlete - Parent - Peer

52,62

Athlete - Coach - Peer

$4,6,9,24,39,41,66,72$

$18,21,28,33,45,61,71$

$2,5,19,30,35,38,44,46,47,53,54,59$

$1-10$

$11-50$

$51-100$

$101-200$

$201-300$

$301-500$

$500-1,000$

Over 1,000

$1,7,10,14,15,17,20,25,27,29,34,36,37,48,60,62,63,64,67$, $68,69,70$

$8,11,12,16,23,26,32,37,42,43,50,51,52,56,57,58,73$

$13,22,49,55,65$

3,31

Not Identified

\section{Gender}

Male

Female

Combined

$4,5,29,45,53,56,62,66$

$7,21,28,65$

$1,2,3,6,8,9,10,11,12,13,14,15,16,18,19,20,22,23,24,25$,

8

$26,27,30,31,32,33,34,35,36,37,38,39,40,41,42,43,44,46$,

59

58 $47,48,49,50,51,52,54,55,57,58,60,61,63,64,67,68,69,70$,

Not Identified $71,72,73$

17,59

\section{Competitive Level}




\begin{tabular}{|c|c|c|c|}
\hline Study Characteristics & Reference Number & Samples & $\mathbf{K}$ \\
\hline Recreational & $9,58,68,70,71$ & 5 & \\
\hline High School/College & 57 & 1 & \\
\hline Club (Non Professional) & $5,10,16,21,40,42,45,52,56,61,63,64,66,67,69$ & 15 & \\
\hline Elite & $3,4,6,8,17,18,19,20,22,24,28,33,36,39,41,48,73$ & 17 & \\
\hline $\begin{array}{l}\text { (Regional/National/Internati } \\
\text { onal/Olympic) }\end{array}$ & & & \\
\hline Professional & 53,62 & 2 & \\
\hline Amateur & 44 & 1 & \\
\hline Mixed & $\begin{array}{l}1,2,11,12,13,14,15,23,25,26,27,29,30,32,34,35,38,43,46 \\
47,49,50,51,59,60\end{array}$ & 25 & 24 \\
\hline Not Identified & $7,31,37,54,55,65,72$ & 7 & \\
\hline \multicolumn{4}{|l|}{ Type of Sport } \\
\hline Team & $4,5,9,16,21,22,29,45,52,53,56,62,63,64,66,69$ & 16 & \\
\hline Individual & $\begin{array}{l}1,2,10,17,18,19,20,24,28,33,34,35,38,39,40,41,42,44,48 \text {, } \\
54,67\end{array}$ & 21 & \\
\hline Combined & $\begin{array}{l}3,6,8,11,12,13,14,15,23,25,26,27,30,32,36,37,43,46,47 \\
50,51,57,58,59,60,61,71,72,73\end{array}$ & 29 & 28 \\
\hline Not Identified & $7,31,49,55,65,68,70$ & 7 & \\
\hline \multicolumn{4}{|l|}{ Age Profile } \\
\hline 10 & $40,69,70,72$ & 4 & \\
\hline 11 & $10,56,68$ & 3 & \\
\hline 12 & $7,31,63,64,71$ & 5 & \\
\hline 13 & $20,21,30,47$ & 4 & \\
\hline 14 & $2,5,9,29,37,52,55,59,60,62$ & 10 & \\
\hline 15 & $16,22,42$ & 3 & \\
\hline 16 & $19,28,61$ & 3 & \\
\hline 17 & $4,41,53,57$ & 4 & \\
\hline 18 & $6,27,34,35,38,48,54,73$ & 8 & \\
\hline 19 & $14,25,26,39,44$ & 5 & \\
\hline 20 & $8,11,13,43,45,46,49,50$ & 8 & \\
\hline 21 & $1,12,15,33,36,51$ & 6 & 5 \\
\hline 22 & 23,32 & 2 & \\
\hline Mean Age Not Identified & $3,6,17,18,24,65,66,67$ & 8 & \\
\hline
\end{tabular}




\begin{tabular}{|c|c|c|c|}
\hline Study Characteristics & Reference Number & Samples & $\mathbf{K}$ \\
\hline \multicolumn{4}{|l|}{ Location } \\
\hline North America & $\begin{array}{l}4,6,7,8,9,10,16,17,18,19,20,21,33,40,42,52,55,58,59,60 \\
61,63,64,65,66,67,68,69,70\end{array}$ & 29 & \\
\hline Europe & $\begin{array}{l}1,2,3,5,11,12,13,14,15,22,23,24,25,26,27,28,29,30,31 \\
34,35,36,38,39,41,43,44,45,46,47,48,49,50,51,53,54,56 \\
57,62,72,73\end{array}$ & 41 & 40 \\
\hline Australia & 37 & 1 & \\
\hline Other Nations & 2 (Japan) & 1 & \\
\hline Not Identified & 32,71 & 2 & \\
\hline
\end{tabular}

Note $\mathrm{k}=$ number of sample populations

1 = Adie, J. W., \& Jowett, S. (2010); 2 = Alfermann, D., Geisler, G., \& Okade, Y. (2013); 3 = Baxter-Jones, A. D. G., \& Maffulli, N. (2003); 4 = Bruner, M. W., Munroe-Chandler, K. J., \& Spink, K. S. (2008); 5 = Carr, S. (2009); 6 = Côté, J. (1999); 7 = Davison, K. K., \& Jago, R. (2009); 8 = DeFreese, J. D., \& Smith, A. L. (2013); 9 = Dorsch, T. E., Smith, A. L., \& McDonough, M. H. (2009); 10 = Douglas Coatsworth, J., \& Conroy, D. E. (2006); 11 = Felton, L., \& Jowett, S. (2012); 12 = Felton, L., \& Jowett, S. (2012); 13 = Felton, L., \& Jowett, S. (2013); 14 = Freeman, P., Coffee, P., \& Rees, T. (2011); $15=$ Freeman, P., Coffee, P., \& Rees, T. (2011); 16 = Gould, D., Flett, R., \& Lauer, L. (2012); 17 = Gould, D., Lauer, L., Rolo, C., Jannes, C., \& Pennisi, N. (2006); 18 = Gould, D., Lauer, L., Rolo, C., Jannes, C., \& Pennisi, N. (2008); 19 = Gould, D., Tuffey, S., Udry, E., \& Loehr, J. (1996); 20 = Hellstedt, J. C. (1990); 21 = Holt, N. L., Black, D. E., Tamminen, K. A., Fox, K. R., \& Mandlgo, J. L. (2008); 22 = Isoard-Gautheur, S., Guillet-Descas, E., \& Duda, J. L. (2013); 23 = Jowett, S. (2006); 24 = Jowett, S. (2008); 25 = Jowett, S. (2009); 26 = Jowett, S. (2009); 27 = Jowett, S., \& Cramer, D. (2010); $28=$ Jowett, S., \& TimsonKatchis, M. (2005); 29 = Kavussanu, M., White, S. A., Jowett, S., \& England, S. (2011); 30 = Keegan, R., Spray, C., Harwood, C., \& Lavallee, D. (2010); 31 = Keresztes, N., Piko, B. F., Pluhar, Z. F., \& Page, R. M. (2008); 32 = Lafrenière, M. A. K., Jowett, S., Vallerand, R. J., \& Carbonneau, N. (2011); 33 = Lauer, L., Gould, D., Roman, N., \& Pierce, M. (2010); 34 = Le Bars, H., Gernigon, C., \& Ninot, G. (2009); 35 = Le Bars, H., Gernigon, C., \& Ninot, G. (2009); 36 = Lorimer, R., \& Jowett, S. (2009); 37 = Lubans, D. R., Morgan, P. J., \& McCormack, A. (2011); 38 = Nicolas, M., Gaudreau, P., \& Franche, V. (2011); $39=$ Philippe, R. A., Sagar, S. S., Huguet, S., Paquet, Y., \& Jowett, S. (2011); 40 = Power, T. G., \& Woolger, C. (1994); $41=$ Pummell, B., Harwood, C., \& Lavallee, D. (2008); 42 = Raedeke, T. D., \& Smith, A. L. (2004); 43 = Rees, T., \& Freeman, P. (2007); 44 = Rees, T., \& Freeman, P. (2010); $45=$ Rees, T., Freeman, P., Bell, S., \& Bunney, R. (2012); 46 = Rees, T., Freeman, P., Bell, S., \& Bunney, R. (2012); 47 = Rees, T., Freeman, P., Bell, S., \& Bunney, R. (2012); 48 = Rees, T., \& Hardy, L. (2004); 49 = Rees, T., Hardy, L., \& Evans, L. (2007); 50 = Rhind, D., \& Jowett, S. (2012); 51 = Rhind, D., \& Jowett, S. (2012); 52 = Riley, A., \& Smith, A. L. (2011); 53 = Sagar, S. S., Busch, B. K., \& Jowett, S. (2010); 54 = Salguero, A., Gonzalez-Boto, R., Tuero, C., \& Marquez, S. (2003); 55 = Smith, A. L. (1999); 56 = Smith, A. L., Balaguer, I., \& Duda, J. L. (2006); 57 = Smith, A. L., Gustafsson, H., \& Hassmén, P. (2010); 58 = Smith, A. L., Ullrich-French, S., Walker II, E., \& Hurley, K. S. (2006); 59 = Strachan, L., Côté, J., \& Deakin, J. (2009); 60 = Strachan, L., Côté, J., \& Deakin, J. (2009); 61 = Tamminen, K. A., \& Holt, N. L. (2012); 62 = Taylor, I. M., \& Bruner, M. W. (2012); 63 = Ullrich-French, S., \& Smith, A. L. (2006); 64 = Ullrich-French, S., \& Smith, A. L. (2009); 65 = Voorhees, C. C., Murray, D., Welk, G., Birnbaum, A., Ribisl, K. M., Johnson, C. C., Jobe, J. B. (2005); $66=$ Weiss, M. R., \& Fretwell, S. D. (2005); 67 = Weiss, M. R., Kimmel, L. A., \& Smith, A. L. (2001); $68=$ Weiss, M. R., \& Smith, A. L. (1999); $69=$ Weiss, M. R., \& Smith, A. L. (1999); 70 = Weiss, M. R., \& Smith, A. L. (1999); 71 = Weiss, M. R., Smith, A. L., \& Theeboom, M. (1996); $72=$ Wheeler, S. (2012); 73 = Wylleman, P., De Knop, P., Sloore H., Vanden Auweele, Y.,. and Ewing, M.,. (2003) 


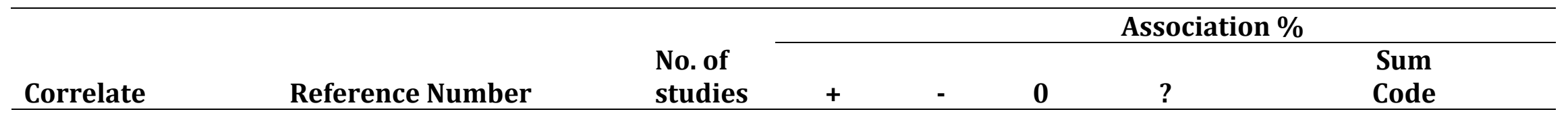

Factors related to social support in youth sport

Social Support Provider Category 1 - Coach Support Correlates

\begin{tabular}{|c|c|c|c|c|c|c|}
\hline Quality of Athlete & $23+, 24=, 25+, 26+, 32+$ & 12 & $11(92)$ & & $1(8)$ & + \\
\hline Relationship & $\begin{array}{l}36+, 39+, 45+, 46+, 47+ \\
50+, 51+\end{array}$ & & & & & \\
\hline Athlete Motivation & $\begin{array}{l}1+, 2=, 11+, 12=, 13=, 16+, \\
22=, 30=, 52+, 56+(\mathrm{m}), 62+ \\
(\mathrm{m}),\end{array}$ & 11 & $7(64)$ & & $4(36)$ & + \\
\hline $\begin{array}{l}\text { Elite Sport } \\
\text { Participation }\end{array}$ & $3+, 4=, 34+, 35+, 41+$ & 5 & $4(80)$ & & $1(20)$ & + \\
\hline Athlete Burnout & $19+, 22+, 59=$ & 3 & $2(67)$ & & $1(33)$ & + \\
\hline Athlete Satisfaction & $32+, 36+, 66=(\mathrm{m})$ & 3 & $2(67)$ & & $1(33)$ & + \\
\hline Athlete Drop Out & $34+, 35+, 54+$ & 3 & $3(100)$ & & & + \\
\hline Athlete & $16+, 39+, 73+$ & 3 & $3(100)$ & & & + \\
\hline Development & & & & & & \\
\hline Social Support Pro & ider Category 2 - Parent Su & port & lates & & & \\
\hline Athlete Motivation & $\begin{array}{l}12-, 13-, 29+(\text { m-elite }), 30+ \\
63+, 64+\end{array}$ & 6 & $4(67)$ & $2(33)$ & & + \\
\hline $\begin{array}{l}\text { Elite Sports } \\
\text { Participation }\end{array}$ & $3+, 6+, 20-, 34-, 35-, 41+$ & 6 & $3(50)$ & $3(50)$ & & $?$ \\
\hline Athlete & $17=, 18=, 33=, 41+, 73+$ & 5 & $2(40)$ & & $3(60)$ & $?$ \\
\hline Development & & & & & & \\
\hline Physical Activity & $7=(f), 31=, 72+$ & 3 & $1(33)$ & & $2(67)$ & + \\
\hline Athlete Drop Out & $34+, 35+, 54+$ & 3 & $3(100)$ & & & + \\
\hline
\end{tabular}




\begin{tabular}{|c|c|c|c|c|c|c|}
\hline \multirow[b]{2}{*}{ Correlate } & \multirow[b]{2}{*}{ Reference Number } & \multirow[b]{2}{*}{$\begin{array}{l}\text { No. of } \\
\text { studies }\end{array}$} & \multicolumn{4}{|c|}{ Association \% } \\
\hline & & & + & $\mathbf{0}$ & ? & $\begin{array}{l}\text { Sum } \\
\text { Code }\end{array}$ \\
\hline Athlete Motivation & $\begin{array}{l}8+(\text { Team-mate }), 30+, 52+ \\
56+(\mathrm{m}), 58+, 62+(\mathrm{m}), 63+ \\
64+\end{array}$ & 8 & $8(100)$ & & & + \\
\hline $\begin{array}{l}\text { Elite Sport } \\
\text { Participation }\end{array}$ & $\begin{array}{l}4+(\mathrm{m}) \text { (Team-mate), } 6= \\
\text { (Sibling), 34+, 35+ }\end{array}$ & 4 & $3(75)$ & & $1(25)$ & + \\
\hline Friendship Quality & $68+, 69+, 70+, 71=$ & 4 & $3(75)$ & & $1(25)$ & + \\
\hline Physical Activity & $\begin{array}{l}7+(\mathrm{f}), 31+(\text { classmates }) \\
55+, 65+(\mathrm{f})\end{array}$ & 4 & $4(100)$ & & & + \\
\hline Athlete Drop Out & $34+, 35+, 54+$ & 3 & $3(100)$ & & & + \\
\hline
\end{tabular}


